\title{
RREB1 Transcription Factor Splice Variants in Urologic Cancer
}

\author{
Matthew D. Nitz, ${ }^{*}$ Michael A. Harding, ${ }^{\dagger}$ \\ Steven C. Smith, ${ }^{\dagger}$ Shibu Thomas, ${ }^{\dagger}$ \\ and Dan Theodorescu ${ }^{\dagger \ddagger}$ \\ From the Departments of Molecular Physiology and Biological \\ Physics* and Urology, ${ }^{\dagger}$ University of Virginia Health Sciences \\ Center, Charlottesville, Virginia; and the University of Colorado \\ Comprehensive Cancer Center, ${ }^{\ddagger}$ Aurora, Colorado
}

RREB1 is an alternatively spliced transcription factor implicated in Ras signaling and cancer. Little is known about the expression of RREB1 isoforms in cell lines or human tumors, or about the clinical relevance of the latter. We have developed tools for IHC of RREB1 protein isoform-specific amplification of RREB1 mRNA and selective knockdown of RREB1 isoforms and use these to provide new information by characterizing RREB1 expression in bladder and prostate cancer cell lines and human tissue samples. Previously described splice variants $\operatorname{RREB1} \alpha, \operatorname{RREB1} \beta$, $\operatorname{RREB} 1 \gamma$, and $\operatorname{RREB1} \delta$ were identified, as well as the novel variant RREB1 $\varepsilon$. Total and isoform-specific mRNA expression was lower in most but not all tumors, compared with normal tissues. RREB1 IHC performed on a bladder cancer TMA did not indicate a relationship between total RREB1 expression and overall survival after radical cystectomy for invasive bladder cancer. In contrast, in vitro proliferation studies using the UMUC-3 bladder cancer cell line after selective isoform-specific knockdown of expression indicate that RREB1 $\alpha$ is not necessary for proliferation, but that RREB1 $\beta$ may be required. These contributions should accelerate progress in the nascent RREB1 field by providing new reagents while also providing clues to the role of RREB1 isoforms in human cancer and raising the possibility of isoform-specific roles in human carcinogenesis and progression. (Am J Pathol 2011, 179:477-486; DOI: 10.1016/j.ajpath.2011.03.038)

The Ras family of GTPases, with their regulators and effectors, have been implicated in tumor progression. ${ }^{1-7}$ We recently found that the Ral (Ras-like) GTPase pathway downstream of Ras plays an important role in blad- der cancer cell migration. ${ }^{8,9}$ Notably, the RREB1 (Rasresponsive element binding protein 1) transcription factor was identified as a putative Ral-regulated gene through batch analysis of promoter sequences in Ral target genes. ${ }^{10}$ Experiments confirmed that Ral manipulation affects RREB1 reporter activity in bladder cancer cells. ${ }^{10}$

The significance of RREB1 continues to be elucidated as studies have found it to function in either the induction or repression of gene expression. Genes induced by RREB1 include those encoding calcitonin, ${ }^{11} \mathrm{FSH},{ }^{12} \mathrm{MT}$ -

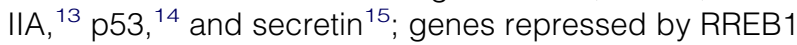
include those encoding angiotensinogen, ${ }^{16}$ HLA-G, ${ }^{17}$ hZIP1, ${ }^{18}$ p16, ${ }^{19}$ and PSA. ${ }^{20}$ RREB1 has also been found to bind nuclear proteins, such as CtBP, ${ }^{21}$ NeuroD, ${ }^{15}$ and androgen receptor (AR). ${ }^{20}$

The initial study of RREB1 found that the gene product bound the calcitonin promoter in medullary thyroid carcinomas in response to Ras. ${ }^{11}$ In bladder cancer, the tumor suppressor p16 is commonly lost as an early event in tumorigenesis, and RREB1 was found to bind and repress transcription of the Cdkn2a locus. ${ }^{19}$ Depletion of RREB1 by siRNA slows cell migration and cell spreading in breast cell lines, ${ }^{22}$ whereas in breast cancer and osteosarcoma cells RREB1 binds the p53 promoter and transactivates p53 expression on DNA damage. ${ }^{14}$ The RREB1 gene is a locus of viral integration for hepatitis $B$ virus in hepatocellular carcinoma. ${ }^{23}$ Furthermore, RREB1 was identified as a potential oncogene in Moloney murine leukemia virus (MuLV) infected p19 $9^{A R F}$ and p53 knockout mice. ${ }^{24}$ Finally, the human RREB1 locus has been found to be amplified in melanoma and is currently an area of intense investigation for its potential in molecular diagnostic testing. ${ }^{25-30}$ In prostate cancer, RREB1 binds the PSA promoter only in association with $A R$ to repress transcription. ${ }^{20}$ In summary, the current literature on RREB1 suggests con-

\footnotetext{
Supported by NIH grant CA143971 (D.T.).

Accepted for publication March 23, 2011.

Supplemental material for this article can be found at http://ajp. amjpathol.org or at doi: 10.1016/j.ajpath.2011.03.038

Current address of S.C.S., University of Michigan, Ann Arbor, Michigan.

Address reprint requests to Dan Theodorescu, M.D., Ph.D., Departments of Surgery and Pharmacology and University of Colorado Comprehensive Cancer Center, Aurora, CO 80045. E-mail: dan.theodorescu@ ucdenver.edu.
} 


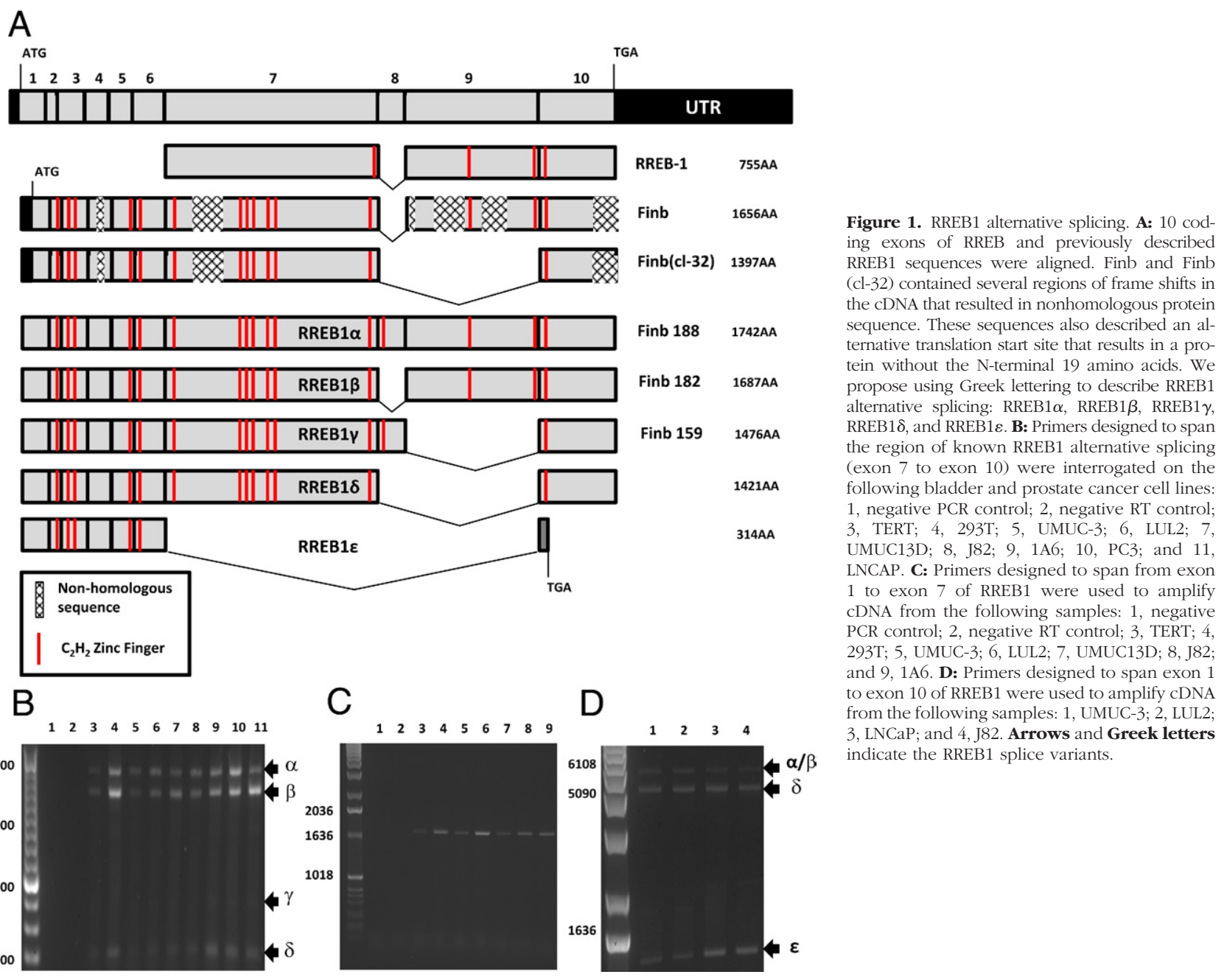

text-dependent phenotypes that may suppress or promote carcinogenesis and tumor progression.

RREB1 is a transcription factor containing between 13 and 15 zinc finger domains, depending on alternative splicing. ${ }^{16}$ It was initially described as a 755 -amino-acid $\mathrm{C}_{2} \mathrm{H}_{2}$ zinc finger protein (RREB-1), ${ }^{11}$ although subsequent analyses in chicken and human cells indicated that RREB1 encodes a longer protein of 1656 (Finb) amino acids (AA) in humans. ${ }^{13,31} \mathrm{~A}$ second variant encoding 1397 amino acids [Finb (cl-32)] with a unique C-terminus was also identified. ${ }^{13}$ Two additional RREB1 C-terminal isoforms exhibiting addition or removal of cassette exons were isolated and designated Finb188 (1742AA) and Finb159 (1476AA). These isoforms exhibit a translation start site $57 \mathrm{bp}$ upstream of the earlier described Finb and Finb (cl-32) isoforms (Figure 1A). ${ }^{16}$ The authors also discovered that Finb contains regions without homology to consensus protein sequence of Finb188. cDNA sequence alignment of Finb and Finb188 reveals that the former does not conform to sequences for the human genome, potentially because of cloning artifacts. ${ }^{16}$ Thus, there is a critical need for consensus on the RREB1 proteins.

Given the number and diversity of known targets of RREB1 signaling, and that splice variants encoding four protein isoforms have already been described, it is likely that RREB1 signaling is mechanistically and phenotypically complex and that expression of isoforms in various proportions could contribute to this complexity. Surprisingly, there has been no comprehensive evaluation of RREB1 isoforms in human cancer cell lines and normal or tumor tissues to date. Furthermore, no study has shown evidence suggestive of isoform-specific phenotypes.

With the present study, we developed tools to evaluate RREB1 isoforms in human bladder and prostate cell lines and human tumors at the RNA and immunohistochemical levels. We then used these tools to evaluate the expression patterns and their clinical relevance in human samples. Here, we present evidence that isoforms have different functional effects on in vitro bladder cancer cell proliferation.

\section{Materials and Methods}

\section{Cell Lines and Human Tissues}

Human cancer cell lines were grown as described previously. ${ }^{32}$ TERT cells ${ }^{33}$ were a gift from Margaret $A$. Knowles. LUL2 cells were isolated from lung tumors by 
successive passages of the UMUC-3 cell line by tail vein injection into nude mice (unpublished data). With strict observance of $\mathrm{NIH}$ and University of Virginia guidelines and with approval of the Institutional Review Board, deidentified flash-frozen and archival tissues of human bladder and prostate cancer and adjacent non-neoplastic epithelia, procured by the University of Virginia Biorepository and Tissue Research Facility, were obtained for analysis of RREB1 expression. The tumor tissue was macrodissected to approximately $80 \%$ purity, as previously described. ${ }^{34}$ The bladder TMA described here has been reported previously. ${ }^{35}$

\section{RNA Isolation, Reverse Transcription, and PCR}

RNA isolation was performed using an RNeasy mini kit (Qiagen, Valencia, CA) and cDNA synthesis using iScript (Bio-Rad, Hercules, CA). Quantitative RT-PCR (qRT-PCR) was performed on CDNA using $\mathrm{iQ}$ SYBR Green Supermix (Bio-Rad). RNA quantification was performed as previously described. ${ }^{36}$ The following primers were used with annealing temperatures: RREB1 (total) forward 5'-CTTCCTATAACTGCCCCC-3', reverse 5'-ATGAGTGGTCGGCTCCTCC-3'; RREB $1 \alpha$ forward 5'-TGGATCCCATGATAGCACAGAC-3', reverse 5'-TGCTCTCTGTCCCGTGAGG-3'; RREB1 $\beta$ forward 5'-CACATGCTCACACACACTGACA-3', reverse 5'-CCGACGGCTGCTCTCTGT-3'; RREB1 $\delta$ forward 5'ACCAACTGCCTGCAGAAGATCA-3', reverse 5'-GTATGGCCITTCCCCAGTGTGT-3'; RREB $1 \varepsilon$ forward 5'-TACAGAACAACCCTTCAATTCCT-3', reverse 5'-TATGGCCTTCCCCTGAG-3'. The PCR for the $5^{\prime}$ and $3^{\prime}$ ends of RREB1 was performed using AccuPrime SuperMix II (Invitrogen, Carlsbad, CA) for 35 cycles with the following primers: RREB1-5' forward 5'-TCGGATTGGCAGAAGGAA-3', reverse 5'-CAGGCTCAGCAGGTTGGT-3'; RREB1 3' forward 5'-CGGAACTCGTACACCAACTG-3', reverse 5'-CGCTGTGGGTGGACTCATTC-3'; RREB1 full length forward 5'-GATCAAGCTTACGTCAAGTTCGCCCGCT-3', reverse 5'-GATCCTCGAGTCACTCCATCCCCACGAG-3'.

\section{Cloning of RREB1}

RREB $1 \delta$ and RREB $1 \varepsilon$ were cloned out of UMUC-3 cells. Sequences were submitted to GenBank: RREB1 $\delta$ (HM369361) and RREB1e (HM369360). Total RNA was isolated as described above and cDNA synthesis using SuperScript III first-strand synthesis supermix (Invitrogen) with $50 \mu \mathrm{mol} / \mathrm{L}$ random hexamers and $1 \mu \mathrm{g}$ total RNA. The PCR reaction also included 10× PfuUltra HF reaction buffer (Agilent Technologies, Foster City, CA), $100 \mathrm{mmol} / \mathrm{L}$ dNTP mix (Agilent), 5\% dimethyl sulfoxide, 1 $\mathrm{mol} / \mathrm{L}$ betaine solution (Sigma-Aldrich, St. Louis, MO). The primers used were as follows: RREB1 cloning forward 5'-GATCATCGATATGACGTCAAGTTCGCCC-3', reverse 5'-GATCTCTAGACTCCATCCCCACGAGCTG-3'. PCR products were isolated in a $1 \%$ agarose gel and purified using a QIAquick gel extraction kit (Qiagen). Isolated products were digested at $37^{\circ} \mathrm{C}$ by the enzymes Clal and Xbal (New England Biolabs, Ipswich, MA) and were ligated into the p3XFLAG-CMV-14 expression vector (Sigma-Aldrich). RREB $1 \alpha$ and RREB $1 \beta,{ }^{16}$ kindly provided by Dr. Aki- yoshi Fukamizu (University of Tsukuba, Tsukuba, Japan), were subcloned into the p3XFLAG-CMV-14.

\section{Antibodies, Immunoblotting, and IHC}

The following antibodies were used in detection of RREB1: anti-RREB1 from GenWay Biotech (cat. no. 18732-2922332; Biotech, San Diego, CA), from Cosmo Bio (cat. no: CBX-CBX00717; Carlsbad, CA; Tokyo, Japan), and from Sigma-Aldrich (cat. no. HPA001756), as well as anti-FLAG (cat. no: F1804; Sigma-Aldrich), anti-tubulin (Santa Cruz Biotechnology, Santa Cruz, CA), and antiTBP (TFIID) (Santa Cruz Biotechnology). Nuclear and cytoplasmic isolates were made with an NE-PER extraction kit (Thermo Scientific, Rockford, IL). Immunoblotting and detection were performed as described previously. ${ }^{8}$ Immunohistochemistry (IHC) was performed on a Dako Autostainer instrument (Dako, Glostrup, Denmark) with the following protocol: antigen retrieval $\left(125^{\circ} \mathrm{C}\right.$, Dako TRS9 buffer, 30 seconds), Dako dual endogenous enzyme block (10 minutes), RREB1 antibody (SigmaAldrich; 1:100 in Dako antibody diluent, 30 minutes), detection (Dako Envision dual link anti-rabbit, 30 minutes), chromogen (Dako diaminobenzidine Dab + substrate, 10 minutes), and counterstain (hematoxylin, 5 minutes). Staining of RREB1 was scored semiquantitatively as negative (absence of staining), low/focal (a blush or positivity of cells $<10 \%$ ), moderate (clearly detectable nuclear staining pattern in up to $50 \%$ of cells), or high (a strong nuclear and/or cytoplasmic positivity in $>50 \%$ of cells).

\section{Transfection and siRNA}

Transient vector transfection was performed using FuGENE 6 transfection reagent (Roche, Basel, Switzerland) according to the manufacturer's instructions. Stable expression was achieved by cutting RREB1-expressing p3XFLAG-CMV-14 vector with the Scal restriction enzyme (New England Biolabs) and transfected with FuGENE 6. Selection was performed for 14 days in 800 $\mu \mathrm{g} / \mathrm{mL}$ of G418 (Geneticin, Invitrogen). Oligofectamine (Invitrogen) was used to transiently transfect siRNA according to the manufacturer's instructions. All siRNA was transfected at a final concentration of $25 \mathrm{nmol} / \mathrm{L}$ : RREB1 total 5'-GGAGUUUGUUUGCAAGUAU-3' and 5'-GUUCAGACCUAUCUUCCAU-3' (used in combination at 12.5 nmol/L), GL2 5'-CGUACGCGGAAUACUUCGAdTdT-3', RREB1 exon 8-1 5'-CCUGAGAAGAAACGGGCUUUU-3', RREB1 exon 8-2 5'-CGCAAACACGGAGUUACCACCUGUU-3', RREB1 exon 8-3 5'-GAUGUUGGAUCCCAUGAUAUU-3', RREB1 exon 9-1 5'-CAGAGAAGAGCGACGAUGAdTdT-3', RREB1 9-2 5'-CCACCAAGCUCAUGGACUUUU-3', and RREB1 exon 9-3 5'-GGAAGAAGGUCUGCAGCGUdTdT-3'.

\section{In Vitro Cell Growth Assays}

In vitro cell growth assays were performed by using Alamar Blue (Invitrogen) fluorescence emission as described previously. ${ }^{37}$ Briefly, Alamar Blue fluorescence was measured at 96 hours after siRNA depletion in UMUC-3 cells. 


\section{Results}

\section{Alternative Splicing Creates a Unique RREB1 Splice Variant}

Using bladder and prostate cancer cell lines as models, primers were designed to interrogate expression of variants in the last four coding exons of RREB1, a region in alternative splicing has been described (Figure 1A). ${ }^{13,16}$ Predicted PCR product sizes for the four RREB1 isoforms characterized thus far were $1237 \mathrm{bp}$ for Finb 188, $1072 \mathrm{bp}$ for Finb182 (RREB-1, Finb), 439 bp for Finb159, and 348 bp for Finb (cl-32). In nine cell lines examined, bands corresponding to all four splice variants were identified (Figure 1B). Each band was sequenced to confirm the PCR products corresponded to the predicted variant. To examine whether the first six identified coding exons of RREB1 transcripts underwent alternative splicing, primers spanning from the first to the seventh coding exon were tested on seven cell lines. Each cell line showed a single band, leading us to conclude that alternative splic- ing of RREB1 occurs predominantly in the exon 6 to exon 10 region of the RNA (Figure $1 \mathrm{C}$ ).

To search for novel splice variants, primers were designed to interrogate all 10 coding exons (Figure 1B). PCR products for Finb188/182 and Finb (Cl-32) were identified, as well as a novel variant migrating at a much smaller size (Figure 1D). Sequencing of this band revealed it to be a novel isoform of RREB1, lacking coding exons 7,8 , and 9 and causing a frame shift in exon 10 , resulting in a loss of a $\mathrm{C}_{2} \mathrm{H}_{2}$ zinc finger and a new translation stop site. Given these findings, we propose the following nomenclature for the RREB1 splice variants: RREB $1 \alpha$, RREB $1 \beta$, RREB $1 \gamma$, RREB1 $\delta$, and RREB1 $\varepsilon$ (Figure $1 \mathrm{~A}$ ).

\section{RREB1 mRNA Expression in Bladder and Prostate Cell Lines}

To evaluate RREB1 isoform expression, we developed primers for qRT-PCR that allow specific amplification of
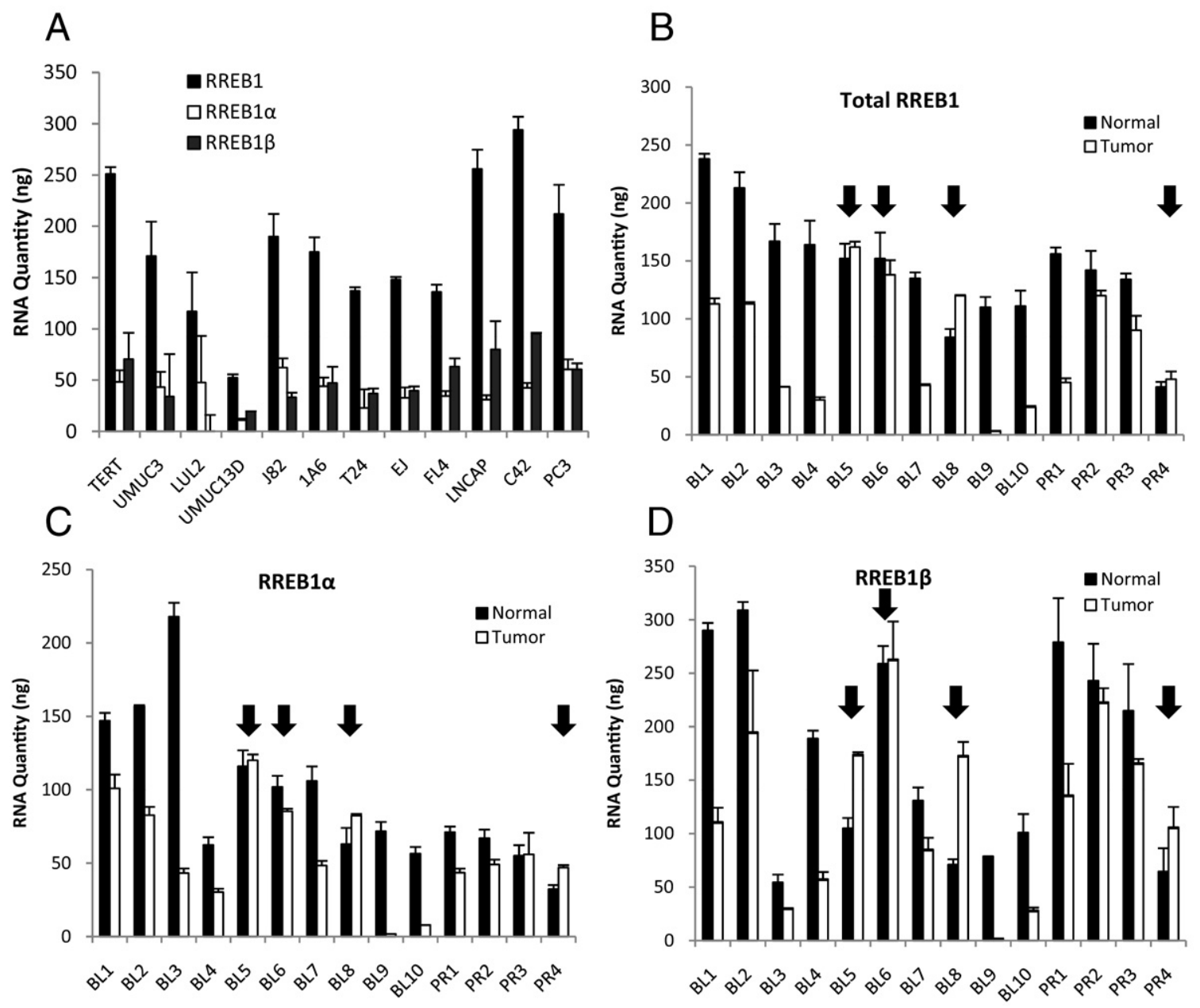

Figure 2. RREB1 transcripts in bladder tumors and cancer cell lines. A: mRNA expression of total RREB1, RREB1 $\alpha$, and RREB1 $\beta$ was measured in bladder and prostate cancer cell lines. RNA quantities cannot be compared among total RREB1, RREB1 $\alpha$, and RREB1 $\beta$, because the levels were calculated on unique standard curves for each primer pair. B: Total RREB1 expression was measured in paired normal and cancer (tumor) urothelial bladder (BL) and prostate (PR) tissues, using primers that span exons 2 and 3 of RREB1, an area lacking alternative splicing. Arrows indicate samples in which RREB1 expression is greater in the tumor than in the paired normal tissue. $\mathbf{C}$ and D: RNA expression of the RREB1 $\alpha$ and RREB1 $\beta$ splice variants was measured using primers targeting base pairs at unique splice junctions. 
each isoform. These primers were used in conjunction with primers spanning the second and third exons, the area we found not to be involved in differential splicing, to detect total RREB1 mRNA expression. We examined one telomerase (TERT) immortalized urothelial cell line, ${ }^{33}$ five urothelial bladder cancer cell lines, and two prostate cancer cell lines. The data presented in Figure 1B, as well as the use of isoform-specific primers to estimate relative abundance of isoforms, demonstrated that RREB $1 \alpha$ and RREB1 $\beta$ comprised the vast majority of total RREB1 mRNA (see Supplemental Figure S1 at $h t t p: / /$ ajp.amjpathol.org). Expression of RREB1 $\gamma$ was so low as to not be reliably quantifiable. Expression of RREB $1 \delta$ typically was only $1 \%$ to $4 \%$, and RREB $1 \varepsilon$ expression was $<1 \%$ of total RREB1. For further studies, therefore, we focused on total RREB1, RREB $1 \alpha$, and RREB1 $\beta$. The expression levels for total RREB1, RREB $1 \alpha$, and RREB $1 \beta$ in cell lines were variable (Figure 2A). Notably, the total RREB1 expression is higher in the nontransformed TERT urothelial cell line than in all of the urothelial (bladder) cancer cell lines.

Next we examined paired human normal and cancerous bladder $(n=10)$ and prostate $(n=4)$ tissues for total RREB1 (Figure 2B), RREB1 $\alpha$ (Figure 2C), and RREB1 $\beta$ (Figure 2D) mRNA expression. Of 10 bladder cancers, 7 samples had lower total RREB1 expression, as well as lower expression of the specific $\alpha$ and $\beta$ isoforms, than their normal counterparts $(P=0.005)$, whereas 3 samples (indicated by arrows in Figure 2) demonstrated similar or higher total RREB1, RREB $1 \alpha$, and RREB1 $\beta$ isoform expression. Of the four prostate cancer samples, three demonstrated a decrease in total RREB1 expression and one had an increase in total RREB1 expression, compared with its normal counterpart $(P=0.22)$.

\section{Detection and Cellular Localization of RREB1 Protein}

The expression of RREB1 splice variants at the protein level has not been examined previously. A major obstacle appears to be the lack of a well-characterized antibody. To define the sensitivity and specificity of three commercial RREB1 antibodies, we cloned RREB $1 \alpha$, RREB1 $\beta$, RREB1 $\delta$, and RREB $1 \varepsilon$ into a C-terminal 3X-FLAG tagged vector. (RREB1 $\gamma$ was excluded because it was undetectable in the cell lines and tissues we examined.) These constructs were transfected into 293T cells and their expression was confirmed by anti-FLAG antibody (Figure 3A). The three RREB1 antibodies were evaluated on these lysates. Two antibodies (from Cosmo Bio and GenWay) detected RREB $1 \alpha$ and RREB $1 \beta$, the GenWay antibody also detecting RREB1 $\delta$. The Cosmo Bio antibody suffered from low sensitivity in detecting endogenous RREB1, and the GenWay antibody had higher nonspecific binding (see Supplemental Figure S2 at http:// ajp.amjpathol.org). The Sigma-Aldrich antibody had robust detection of RREB $1 \alpha$, RREB $1 \beta$, and RREB $1 \delta$ tagged transgenes (Figure $3 A$ ). Support for the specificity of the antibody was provided by observing decreases in endogenous bands of appropriate sizes to the splice variants RREB $1 \alpha$, RREB $1 \beta$, and RREB $1 \delta$ on treatment with SiRNA to total RREB1 in UMUC-3 cells (Figure 3B).

To determine which protein species detected by the antibody corresponded to each RREB1 splice variant, we designed siRNAs targeting specific RREB1 exons. In parallel, the nuclei and cytosol were fractionated to examine the subcellular localization of specific variants (because this had not been shown previously). ${ }^{13}$ RREB1 seems to localize primarily in the nucleus (Figure $3 \mathrm{C}$ ). siRNA to exon 8 knocks down the RREB $1 \alpha$ and RREB $1 \gamma$ splice

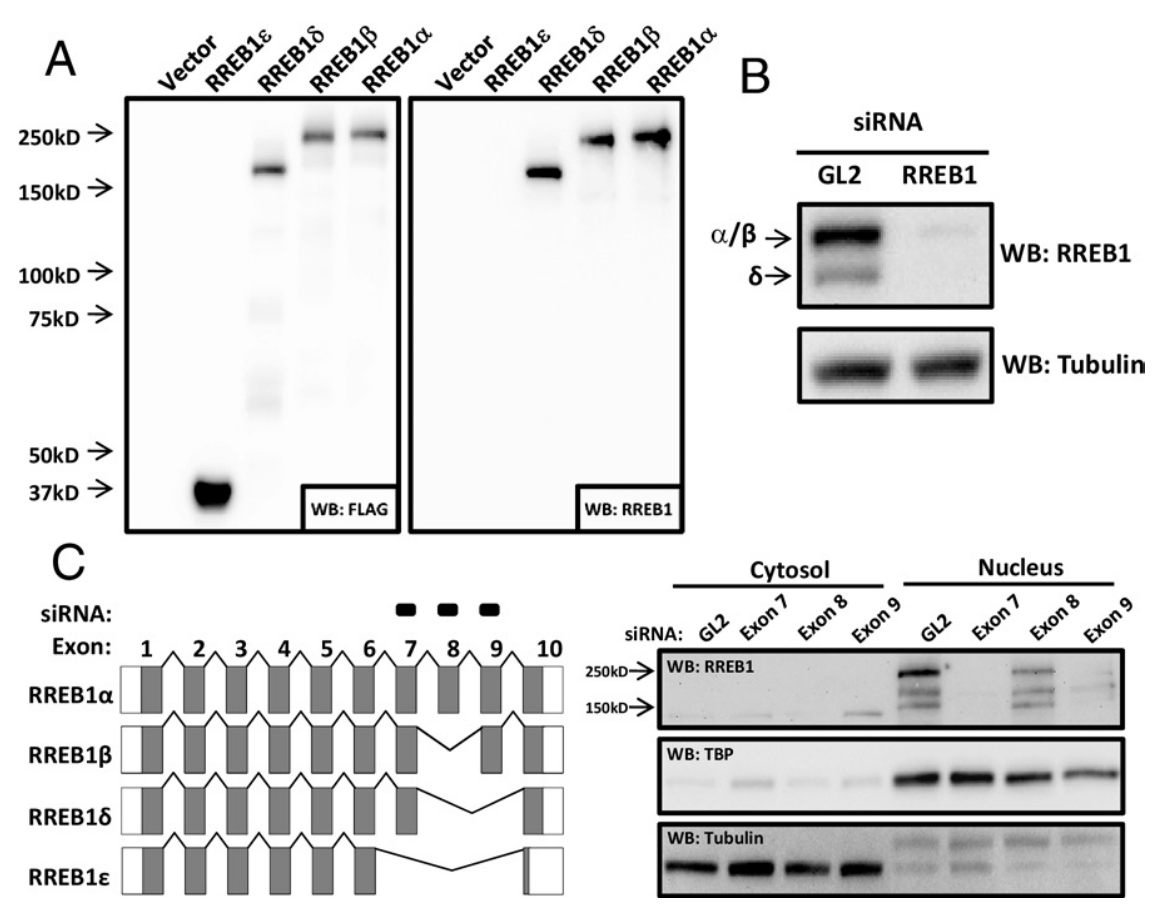

Figure 3. Detection of RREB1 protein isoforms in human bladder cancer cells. A: RREB1 isoforms were either isolated from UMUC-3 cells (Isoforms $\delta$ and $\varepsilon$ ) or received as a gift from Dr. Akiyoshi Fukamizu (University of Tsukuba, Tsukuba, Japan) (isoforms $\alpha$ and $\beta$ ). The splice variants were cloned into a C-terminal 3XFLAGtagged expression construct and expressed in 293T cells. Detection with anti-FLAG (1:1000) or anti-RREB1 (1:1000) (Sigma-Aldrich) antibody is shown. B: RREB1 (total) siRNA, designed to knock down all splice variants, was transfected into UMUC-3 cells. RREB1 antibody (Sigma-Aldrich) detection $(1: 1000)$ on Western blot is shown. C: siRNAs targeting exons 7,8 , or 9 were transfected into UMUC-3 cells. Cytoplasmic and nuclear fractions were isolated after 96 hours and RREB1 protein splice variants were detected on Western blot (1:1000) (Sigma-Aldrich). 
variants. Because RREB1 $\gamma$ mRNA is undetectable, all measurable protein depleted by siRNA to exon 8 represents RREB $1 \alpha$. Exon 8 siRNA decreased the intensity of the largest band (Figure 3C), which, based on size ( 250 $\mathrm{kDa}$ ), is likely RREB $1 \alpha$. siRNA to exon 9, which depletes RREB $1 \beta$ in addition to RREB $1 \alpha$, resulted in an elimination of the largest RREB1 band, which (given only a 3\% difference in amino acid content between the splice variants) likely represents both RREB $1 \alpha$ and RREB $1 \beta$. Surprisingly, a second band at $\sim 150 \mathrm{kDa}$ was also knocked down with exon 9 siRNA. This band could represent a unique RREB1 isoform, which is either generated by an unknown pre-mRNA splicing event that has yet to be identified or is an alternative translation product from the RREB $1 \beta$ isoform. Finally, siRNA to exon 7 , which knocks down RREB $1 \alpha$, RREB $1 \beta$, and RREB $1 \delta$, eliminated the upper band of RREB $1 \alpha$ and RREB $1 \beta$ and the second largest band ( $200 \mathrm{kDa})$, which migrates at the same size as the cloned RREB1 $\delta$ mRNA. The presence of the cytosolic band at $\sim 140 \mathrm{kDa}$ that appears to disappear with siRNA to exon 8 may also represent another unique RREB1 isoform, one that has yet to be identified. The Sigma-Aldrich RREB1 antibody showed the greatest sensitivity and specificity in detecting the exogenously and endogenous isoforms, and therefore it was used in all subsequent experiments.
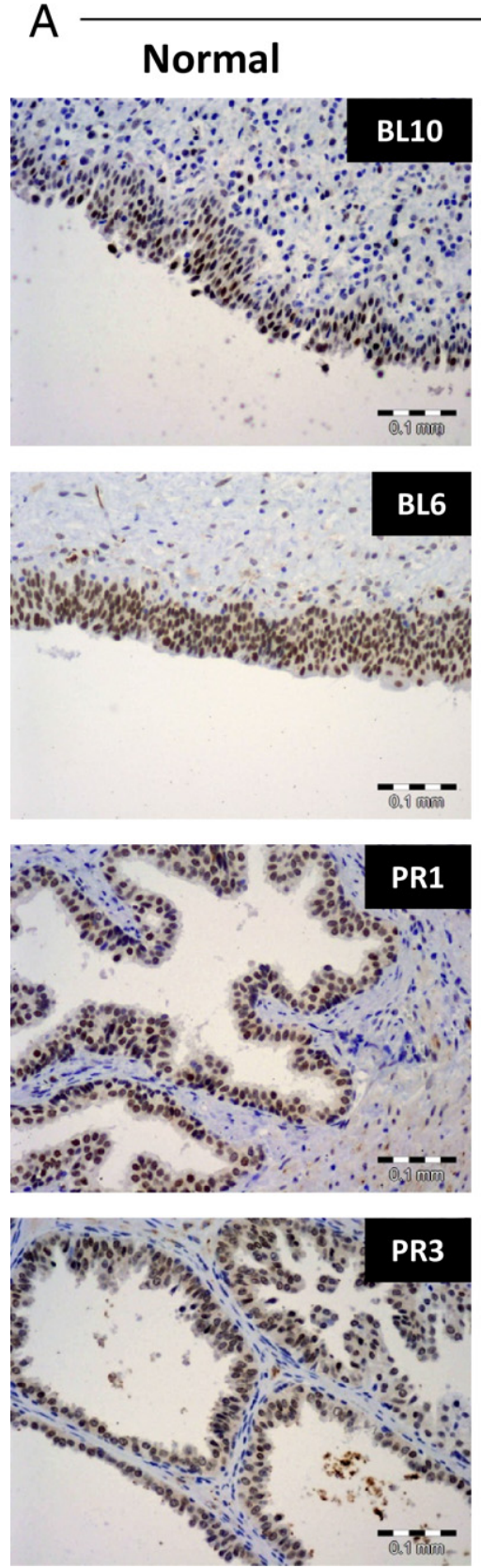

Cancer
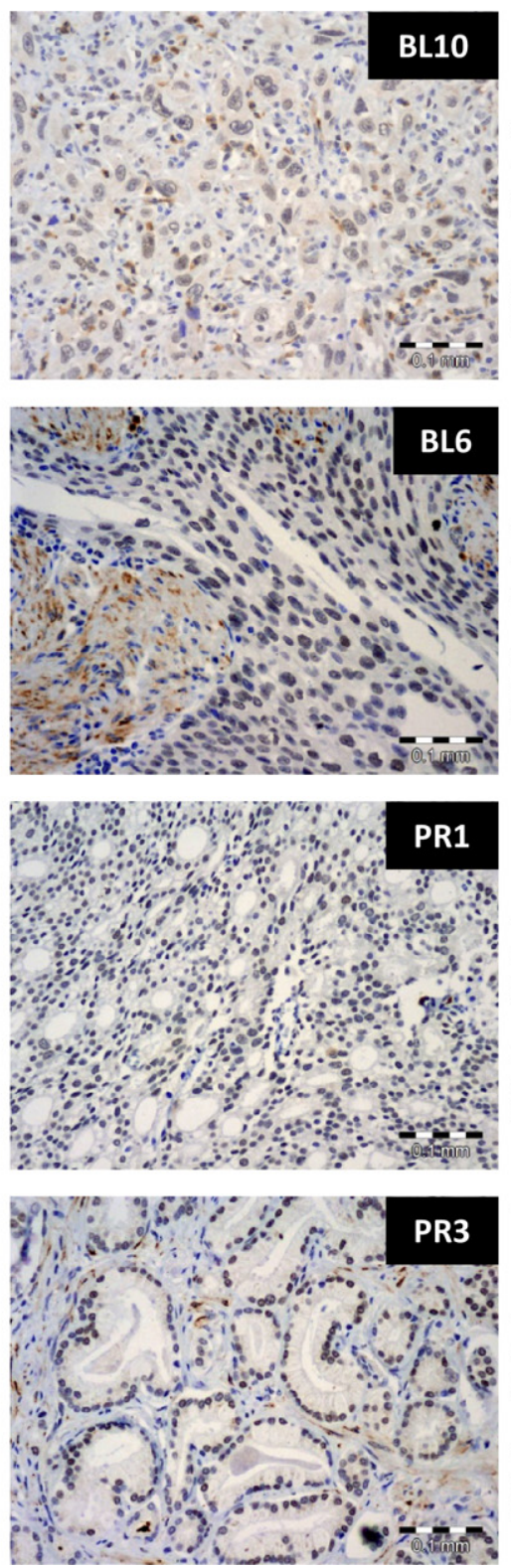

B

Total RREB1 Expression (BL10)

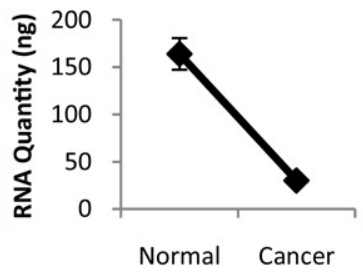

Total RREB1 Expression

(BL6)

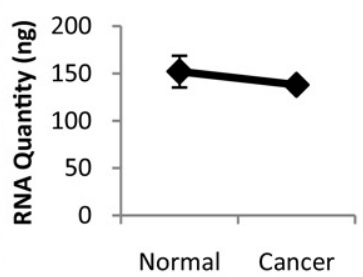

Total RREB1 Expression (PR1)

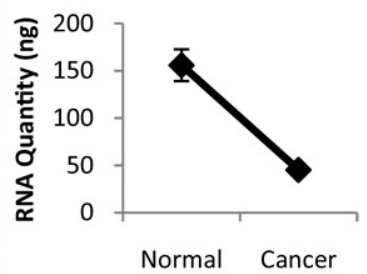

Total RREB1 Expression

(PR3)

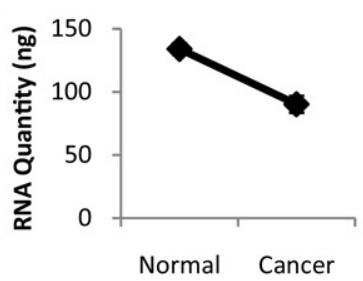

Figure 4. IHC of RREB1 in human carcinoma. A: RREB1 IHC (1:100) (Sigma-Aldrich) of paired normal and cancer tissues for urothelial bladder (BL10 and BL6) and prostate (PR1 and PR3). B: Total RREB1 RNA levels by qRT-PCR from the same tissue as in A. Scale bars: $0.1 \mathrm{~mm}$. 


\section{Expression RREB1 Protein in Normal and Cancerous Bladder and Prostate Tissues}

Next we optimized the Sigma-Aldrich RREB1 antibody for immunohistochemical staining to determine whether the expression patterns and subcellular localization observed in cells reflected those found in human tissue. After optimization, IHC was performed on two samples of bladder cancer and two samples of prostate cancer and adjacent normal tissue. We found a general decrease in RREB1 staining in the malignant tissue, compared with adjacent benign tissue (Figure 4A), a finding consistent with qRT-PCR analysis (Figure 4B). In general, RREB1 staining was strongest in the nucleus (although, as we observed in cell line fractionation experiments, some cytoplasmic expression was also detected).

\section{RREB1 $\beta$ Is Necessary for UMUC-3 Proliferation}

To study a possible RREB1 isoform-specific phenotype, we investigated the effect of total RREB1 knockdown versus specific knockdown of RREB $1 \alpha$ or RREB $1 \alpha$ and RREB $1 \beta$ together on proliferation of the UMUC-3 urothelial cancer cell line. It is not possible to knock down RREB1 $\beta$ specifically, because of a lack of a siRNA sequence in the unique splice junction site. Knockdown of RREB1 (total) using a siRNA targeting a region common to all isoforms inhibited proliferation of UMUC-3 cells (Figure 5A). To determine the isoform specificity of the RREB1 growth phenotype, we tested isoform-specific siRNAs in depletion experiments in UMUC-3. siRNA to exon 8 (exon 8-1), which targets RREB1 $\alpha$, showed no decrease in UMUC-3 growth in vitro (Figure 5A). qRT-
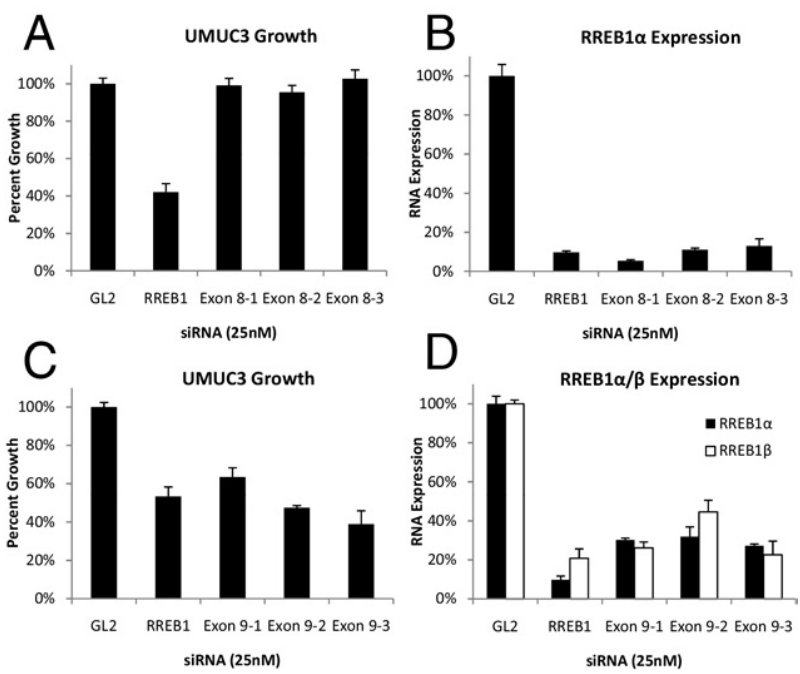

Figure 5. Depletion of RREB1 $\beta$ decreases UMUC-3 growth in vitro. A: UMUC-3 cells were treated with $25 \mathrm{nmol} / \mathrm{L}$ siRNA of control (GL2), RREB1 (all isoforms), and three unique siRNAs targeting exon 8 (8-1, 8-2, and 8-3). Growth was measured 96 hours after siRNA depletion using Alamar Blue and normalized to the GL2 control. B: Real-time PCR for the RREB1 $\alpha$ splice variant was performed for the experiment described in panel A to confirm knockdown of RREB1 $\alpha$. RNA levels were normalized to the GL2 control siRNA. C: UMUC-3 cells were treated with $25 \mathrm{nmol} / \mathrm{L}$ siRNA of control (GL2), RREB1 (all isoforms), and three unique siRNAs targeting exon 9 (9-1, 9-2, and 9-3). D: RREB $1 \alpha$ and RREB1 $\beta$-specific real-time PCR was used to confirm $\operatorname{RREB} 1 \alpha$ and RREB1 $\beta$ knockdown.
PCR for RREB $1 \alpha$ was performed to judge the extent of knockdown and showed $>80 \%$ loss of expression (Figure $5 \mathrm{~B}$ ). To determine whether this effect was specific, we designed two additional siRNAs to separate regions within exon 8 (exon 8-2 and exon 8-3). The additional siRNAs had similar effects on UMUC-3 growth (Figure $5 A$ ), while maintaining efficient knockdown of RREB $1 \alpha$ (Figure 5B). However, siRNA to exon 9 (exon 9-1), which knocks down RREB $1 \alpha$ and RREB $1 \beta$ together, decreased growth similar to that of siRNAs targeting all RREB1 splice variants (Figure $5 \mathrm{C}$ ). Isoform-specific qRT-PCR showed that RREB $1 \alpha$ and RREB $1 \beta$ were robustly depleted in these cells (Figure 5D). Two additional siRNAs were designed to unique regions within exon 9 to confirm the specificity of these phenotypic effects. The additional siRNAs targeted to exon 9 (exon 9-2 and 9-3) showed identical results on UMUC-3 growth (Figure $5 \mathrm{C}$ ).

\section{RREB1 Protein Expression Does Not Predict Overall Survival in Bladder Cancer}

With the knowledge that RREB1 is necessary for proliferation of the bladder cancer cell line UMUC-3, we asked whether expression of RREB1 in bladder cancer tissue is predictive of overall survival. We performed $\mathrm{IHC}$ on a 142-sample $\mathrm{TMA}^{35}$ from patients with bladder cancer who underwent cystectomy. The intensity of RREB1 staining was scored as negative, low/focal, moderate, and high (Figure 6A). A Kaplan-Meier analysis of overall survival for stratified RREB1 expression groupings was plotted (Figure 6B). None of the four RREB1 staining patterns were predictive of survival $(P=0.86)$. Furthermore, RREB1 staining did not correlate with pathological tumor grade $(P=0.62)$, stage (pT) $(P=0.43)$, or nodal metastasis ( $\mathrm{pN})(P=0.69)$ (see Supplemental Table $\mathrm{S} 1$ at http://ajp.amjpathol.org).

\section{Discussion}

Despite its implication in Ras, Ral, p16, p53, and androgen receptor ${ }^{10,11,14,19,20}$ signaling pathways, sparse data exist regarding the nature, expression, or function of RREB1 mRNA and protein in cancer cells. This is the first study to address this gap by describing RREB1 expression in human cancers, as well as the first to examine isoform expression in human tissues and cell lines. We confirmed expression of four previously described mRNA splice variants, clarified prior sequencing artifacts, ${ }^{13,16}$ and identified a novel RREB1 splice variant. For the sake of clarity within the field, we propose a new nomenclature for RREB1 splice variants, ordered from the largest to the smallest protein coding sequence: RREB $1 \alpha$, RREB $1 \beta$, $\operatorname{RREB} 1 \gamma, \operatorname{RREB} 1 \delta$, and RREB1 $\varepsilon$.

Characterization of currently available RREB1 antibodies failed to detect the new RREB1 1 isoform, or to specifically detect any single RREB1 isoform. However, we could readily detect proteins corresponding to the most abundant RREB1 mRNA species. The comparison of RREB1 expression as measured by $\mathrm{IHC}$ and its correlation with clinical outcome did not reveal a relationship to 

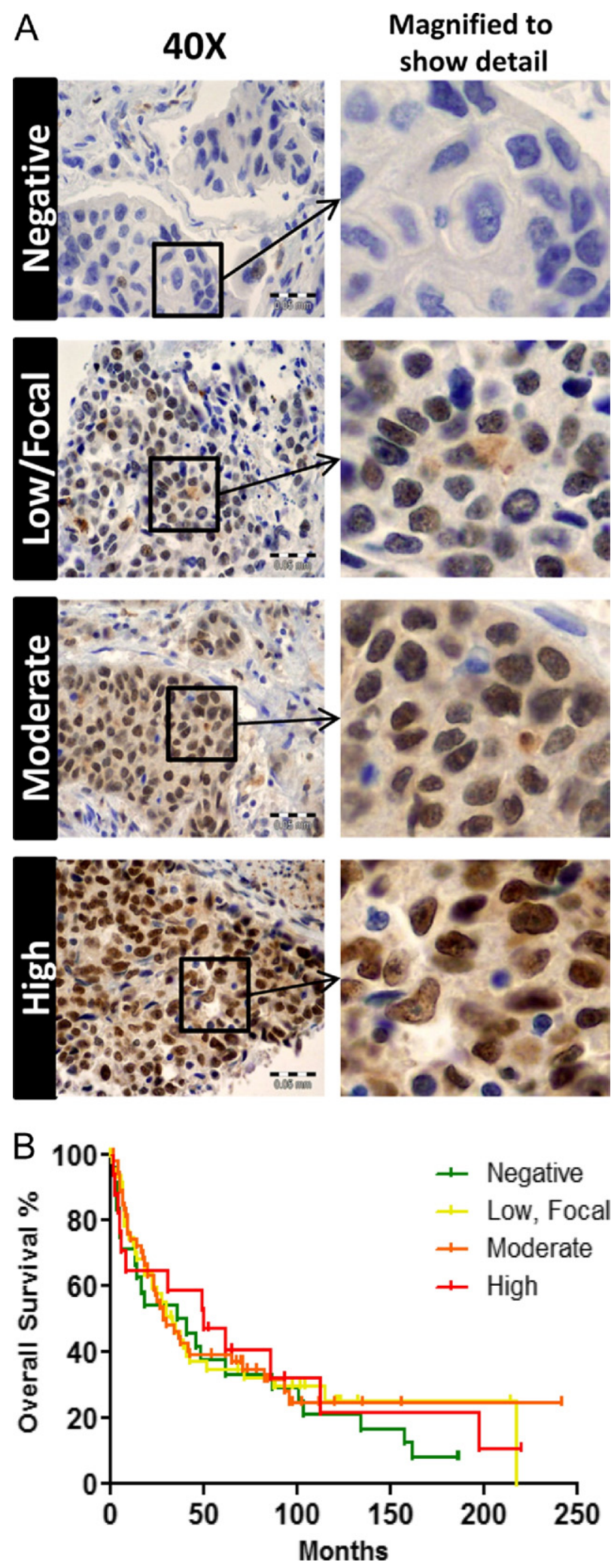

Figure 6. Total RREB1 expression in bladder cancer does not predict overall survival. A: A TMA of archived bladder cancers $(n=142)$ was used to assay for RREB1 expression. Representative examples of RREB1 expression grading are shown, as described under Materials and Methods (negative, low/ focal, moderate, and high). B: Survival data of patients whose tumors comprised the bladder cancer TMA was used to generate a Kaplan-Meier analysis comparing RREB1 staining versus overall survival. RREB1 staining did not significantly correlate with this clinical parameter $(P=0.86, \log$ rank). disease-free survival for bladder cancer patients. The antibody used for the TMA cannot differentiate between expression of RREB $1 \alpha$ and RREB $1 \beta$, and indeed no such antibodies exist at this time. Given our results with isoform-specific GRT-PCR in bladder cancers, and the possibility of differential effects of RREB1 in subsets of tumors and isoform-specific effects, it is possible that expression of a specific RREB1 isoform in a particular subset of patients will be predictive of disease survival. These findings indicate the need for further reagent development as hypotheses for RREB1 function become more sophisticated.

Given its associations with cancer signaling, we suspected that RREB1 expression would be altered in tumors. By using qRT-PCR for the most abundant isoforms, namely RREB $1 \alpha$ and RREB $1 \beta$, as well as IHC for RREB1 protein, we found that RREB1 expression was lower in tumors, compared with histologically similar but untransformed tissue from the same patient. This suggests that loss of RREB1 expression is associated with transformation.

Although most of the cancers examined by qRT-PCR showed decreased RREB1 expression, there were exceptions. In tumors in which total RREB1 mRNA expression was seen to increase compared with normal tissue, we observed that the RREB1 $\beta$ mRNA increased more than the RREB $1 \alpha$ isoform. Although the number of samples examined is small, these observations at least suggest the possibility that RREB $1 \beta$ is preferentially increased in some tumors, relative to RREB $1 \alpha$. This allowed us to hypothesize that RREB1 may have a growth-promoting effect in some subset of tumors, and that this phenotype may be largely mediated by the $\beta$ isoform. Our in vitro experiments with selective RREB1 knockdown in UMUC-3 bladder cancer cells support this hypothesis. In UMUC-3 cells, RREB1 $\alpha$ was not required for cell proliferation, whereas knockdown of both $\alpha$ and $\beta$ inhibited proliferation. The most parsimonious explanation of this result is that RREB1 $\beta$ is necessary for proliferation but that RREB $1 \alpha$ is dispensable, at least in the context of UMUC-3 cells. This result also implies that UMUC-3 cells are more representative of a subset of tumors in which RREB1 expression could promote tumor growth.

The recently reported interaction of RREB 1 with AR in prostate cancer cells may provide a clue as to why decreased RREB1 expression is associated with this particular tumor type. Mukhopadhyay et al ${ }^{20}$ reported that RREB1 binds AR and inhibits its function as a transcription factor. In addition, RREB1 binding and inhibition of AR activity was relieved by activated Ras signaling. Because increased androgen signaling is thought to play a central role in prostate cancer tumorigenesis, the decreased RREB1 expression we observe in prostate cancer specimens may result in heightened AR activity. Ours is the first report of diminished RREB1 expression in prostate cancer clinical samples, and the findings suggest that the molecular interactions described by Mukhopadhyay et $\mathrm{al}^{20}$ from in vitro studies may be operational in actual human prostate tumors.

Other signaling targets may account for decreased RREB1 expression in tumor types in which AR is not an 
obvious contributing factor. Liu et al ${ }^{14}$ reported that transcription of the p53 tumor suppressor gene in response to genotoxic stress is dependent on RREB1 binding to the p53 promoter in a variety of cancer cell lines, including osteosarcoma, breast and colon cancer cells. Apoptosis induced by p53 in response to DNA damage was also RREB1-dependent. It is possible, therefore, to hypothesize that a decrease in RREB1 in tumors would result in resistance to DNA-damaging chemotherapy agents used in treating urothelial tumors. This hypothesis can now be tested in bladder and other cancers using the tools we have developed.

The work presented here provides both new tools for investigating RREB1 expression and insights into its function. Our observations also provide interesting and testable hypotheses regarding the role of RREB 1 and $A R$ in prostate cancer progression, as well as that of RREB1 in resistance to chemotherapy. This work will also, we hope, provide an impetus for future studies to differentiate between isoform-specific effects in the nascent field of RREB1 signaling in cancer.

\section{Acknowledgments}

We thank Dr. Christopher Moskaluk and the University of Virginia Biorepository and Tissue Research Facility (BTRF) for their assistance in obtaining deidentified human clinical specimens for evaluation.

\section{References}

1. Traynor P, McGlynn LM, Mukhergee R, Grimsley SJ, Bartlett JM, Edwards J: An increase in N-Ras expression is associated with development of hormone refractory prostate cancer in a subset of patients. Dis Markers 2008, 24:157-165

2. Erlich S, Tal-Or P, Liebling R, Blum R, Karunagaran D, Kloog $Y$, Pinkas-Kramarski R: Ras inhibition results in growth arrest and death of androgen-dependent and androgen-independent prostate cancer cells. Biochem Pharmacol 2006, 72:427-436

3. Weber MJ, Gioeli D: Ras signaling in prostate cancer progression. J Cell Biochem 2004, 91:13-25

4. Min J, Zaslavsky A, Fedele G, McLaughlin SK, Reczek EE, DE Raedt T, Guney I, Strochlic DE, Macconaill LE, Beroukhim R, Bronson RT, Ryeom S, Hahn WC, Loda M, Cichowski K: An oncogene-tumor suppressor cascade drives metastatic prostate cancer by coordinately activating Ras and nuclear factor-kappaB. Nat Med 2010, 16:286-294

5. Oxford G, Theodorescu D: The role of Ras superfamily proteins in bladder cancer progression. J Urol 2003, 170:1987-1993

6. Nguyen PL, Swanson PE, Jaszcz W, Aeppli DM, Zhang G, Singleton TP, Ward S, Dykoski D, Harvey J, Niehans GA: Expression of epidermal growth factor receptor in invasive transitional cell carcinoma of the urinary bladder. A multivariate survival analysis. Am J Clin Pathol 1994, 101:166-176

7. Theodorescu D, Cornil I, Fernandez BJ, Kerbel RS: Overexpression of normal and mutated forms of HRAS induces orthotopic bladder invasion in a human transitional cell carcinoma. Proc Natl Acad Sci USA 1990, 87:9047-9051

8. Oxford G, Owens CR, Titus BJ, Foreman TL, Herlevsen MC, Smith SC, Theodorescu D: RalA and RalB: antagonistic relatives in cancer cell migration. Cancer Res 2005, 65:7111-7120

9. Gildea JJ, Harding MA, Seraj MJ, Gulding KM, Theodorescu D: The role of Ral A in epidermal growth factor receptor-regulated cell motility. Cancer Res 2002, 62:982-985
10. Oxford G, Smith SC, Hampton G, Theodorescu D: Expression profiling of Ral-depleted bladder cancer cells identifies RREB-1 as a novel transcriptional Ral effector. Oncogene 2007, 26:7143-7152

11. Thiagalingam $A$, De Bustros $A$, Borges $M$, Jasti $R$, Compton $D$, Diamond L, Mabry M, Ball DW, Baylin SB, Nelkin BD: RREB-1, a novel zinc finger protein, is involved in the differentiation response to Ras in human medullary thyroid carcinomas. Mol Cell Biol 1996, 16:53355345

12. Xing W, Sairam MR: Cross talk of two Krupple transcription factors regulates expression of the ovine FSH receptor gene. Biochem Biophys Res Commun 2002, 295:1096-1101

13. Fujimoto-Nishiyama A, Ishii S, Matsuda S, Inoue J, Yamamoto T: A novel zinc finger protein, Finb, is a transcriptional activator and localized in nuclear bodies. Gene 1997, 195:267-275

14. Liu H, Hew HC, Lu ZG, Yamaguchi T, Miki Y, Yoshida K: DNA damage signalling recruits RREB-1 to the p53 tumour suppressor promoter. Biochem J 2009, 422:543-551

15. Ray SK, Nishitani J, Petry MW, Fessing MY, Leiter AB: Novel transcriptional potentiation of BETA2/NeuroD on the secretin gene promoter by the DNA-binding protein Finb/RREB-1. Mol Cell Biol 2003, 23:259-271

16. Date S, Nibu Y, Yanai K, Hirata J, Yagami K, Fukamizu A: Finb, a multiple zinc finger protein, represses transcription of the human angiotensinogen gene. Int J Mol Med 2004, 13:637-642

17. Flajollet S, Poras I, Carosella ED, Moreau P: RREB-1 is a transcriptional repressor of HLA-G. J Immunol 2009, 183:6948-6959

18. Milon BC, Agyapong A, Bautista R, Costello LC, Franklin RB: Ras responsive element binding protein-1 (RREB-1) down-regulates hZIP1 expression in prostate cancer cells. Prostate 2010, 70:288-296

19. Zhang S, Qian X, Redman C, Bliskovski V, Ramsay ES, Lowy DR, Mock BA: p16 INK4a gene promoter variation and differential binding of a repressor, the ras-responsive zinc-finger transcription factor, RREB. Oncogene 2003, 22:2285-2295

20. Mukhopadhyay NK, Cinar B, Mukhopadhyay L, Lutchman M, Ferdinand AS, Kim J, Chung LW, Adam RM, Ray SK, Leiter AB, Richie JP, Liu BC, Freeman MR: The zinc finger protein ras-responsive element binding protein- 1 is a coregulator of the androgen receptor: implications for the role of the Ras pathway in enhancing androgenic signaling in prostate cancer. Mol Endocrinol 2007, 21:2056-2070

21. Shi Y, Sawada J, Sui G, Affar el B, Whetstine JR, Lan F, Ogawa H, Luke MP, Nakatani Y: Coordinated histone modifications mediated by a CtBP co-repressor complex. Nature 2003, 422:735-738

22. Melani M, Simpson KJ, Brugge JS, Montell D: Regulation of cell adhesion and collective cell migration by hindsight and its human homolog RREB1. Curr Biol 2008, 18:532-537

23. Tamori A, Yamanishi $Y$, Kawashima S, Kanehisa M, Enomoto $M$, Tanaka H, Kubo S, Shiomi S, Nishiguchi S: Alteration of gene expression in human hepatocellular carcinoma with integrated hepatitis $B$ virus DNA. Clin Cancer Res 2005, 11:5821-5826

24. Uren AG, Kool J, Matentzoglu K, de Ridder J, Mattison J, van Uitert M, Lagcher W, Sie D, Tanger E, Cox T, Reinders M, Hubbard TJ, Rogers J, Jonkers J, Wessels L, Adams DJ, van Lohuizen M, Berns A: Large-scale mutagenesis in p19(ARF)- and p53-deficient mice identifies cancer genes and their collaborative networks. Cell 2008, 133: $727-741$

25. Morey AL, Murali R, McCarthy SW, Mann GJ, Scolyer RA: Diagnosis of cutaneous melanocytic tumours by four-colour fluorescence in situ hybridisation. Pathology 2009, 41:383-387

26. Gerami P, Wass A, Mafee M, Fang Y, Pulitzer MP, Busam KJ: Fluorescence in situ hybridization for distinguishing nevoid melanomas from mitotically active nevi. Am J Surg Pathol 2009, 33:1783-1788

27. Pouryazdanparast $P$, Newman M, Mafee M, Haghighat Z, Guitart J, Gerami P: Distinguishing epithelioid blue nevus from blue nevus-like cutaneous melanoma metastasis using fluorescence in situ hybridization. Am J Surg Pathol 2009, 33:1396-1400

28. Gerami P, Mafee M, Lurtsbarapa T, Guitart J, Haghighat Z, Newman $M$ : Sensitivity of fluorescence in situ hybridization for melanoma diagnosis using RREB1, MYB, Cep6, and 11q13 probes in melanoma subtypes. Arch Dermatol 2010, 146:273-278

29. Busam KJ, Fang Y, Jhanwar SC, Pulitzer MP, Marr B, Abramson DH: Distinction of conjunctival melanocytic nevi from melanomas by fluorescence in situ hybridization. J Cutan Pathol 2010, 37:196-203 
30. Gaiser T, Kutzner H, Palmedo G, Siegelin MD, Wiesner T, Bruckner T, Hartschuh W, Enk AH, Becker MR: Classifying ambiguous melanocytic lesions with FISH and correlation with clinical long-term follow up. Mod Pathol 2010, 23:413-419

31. Miyake JH, Szeto DP, Stumph WE: Analysis of the structure and expression of the chicken gene encoding a homolog of the human RREB-1 transcription factor. Gene 1997, 202:177-186

32. Lee JK, Havaleshko DM, Cho H, Weinstein JN, Kaldjian EP, Karpovich J, Grimshaw A, Theodorescu D: A strategy for predicting the chemosensitivity of human cancers and its application to drug discovery. Proc Natl Acad Sci USA 2007, 104:13086-13091

33. Chapman EJ, Hurst CD, Pitt E, Chambers P, Aveyard JS, Knowles MA: Expression of hTERT immortalises normal human urothelial cells without inactivation of the p16/Rb pathway. Oncogene 2006, 25:5037-5045
34. Titus B, Frierson HF Jr, Conaway M, Ching K, Guise T, Chirgwin J, Hampton G, Theodorescu D: Endothelin axis is a target of the lung metastasis suppressor gene RhoGDI2. Cancer Res 2005, 65:73207327

35. Smith SC, Nicholson B, Nitz M, Frierson HF Jr, Smolkin M, Hampton G, El-Rifai W, Theodorescu D: Profiling bladder cancer organ sitespecific metastasis identifies LAMC2 as a novel biomarker of hematogenous dissemination. Am J Pathol 2009, 174:371-379

36. Nitz MD, Harding MA, Theodorescu D: Invasion and metastasis models for studying RhoGDI2 in bladder cancer. Methods Enzymol 2008, 439:219-233

37. Havaleshko DM, Cho H, Conaway M, Owens CR, Hampton G, Lee JK, Theodorescu D: Prediction of drug combination chemosensitivity in human bladder cancer. Mol Cancer Ther 2007, 6:578-586 